Alla Paskovaty

Stephen M. Pastores

Zivile Gedrimaite

Natalie Kostelecky

Elyn R. Riedel

Susan K. Seo

\section{Antimicrobial de-escalation in septic cancer patients: is it safe to back down?}

Accepted: 6 August 2015

Published online: 22 August 2015

(C) The Author(s) 2015. This article is published with open access at

Springerlink.com

Electronic supplementary material The online version of this article (doi: 10.1007/s00134-015-4016-6) contains supplementary material, which is available to authorized users.

Dear Editor,

Antimicrobial stewardship programs

(ASP) aim for de-escalation of initial broad-spectrum antibiotics to reduce selective pressure, toxicity, and costs. The literature on antimicrobial deescalation in septic cancer patients is scarce. We retrospectively examined the frequency and outcomes of antimicrobial de-escalation in 105 adult cancer patients admitted to a 20-bed intensive care unit (ICU) with severe sepsis from the Urgent Care Center (UCC) at Memorial Sloan Kettering Cancer Center, New York, NY between January 2008 and March 2013 (eSupplement Fig. 1). The hospital has an active ASP that developed local sepsis guidelines with the UCC and ICU. De-escalation was defined as discontinuing or narrowing of the regimen by ICU day 5 [1]. Primary outcomes were length of stay (LOS) (ICU, hospital) and allcause mortality (ICU, hospital, 28-day).

Nearly all study patients (96\%) were on empiric combination therapy on ICU admission; 61 (58 \%) of 105 patients had therapy de-escalated. The mean number of antibiotics per patient was $3 \pm 0.8$ in both groups on ICU admission. By ICU day 5, the mean number of antibiotics remained at $3 \pm 0.9$ in the non de-escalation group, while the mean number of antibiotics dropped to $1.5 \pm 0.8$ in the de-escalation group. While the average duration of antibiotic therapy was the same for both groups (Table 1), durations of certain antibiotics (e.g., resistant gram-positive agents, anti-pseudomonal betalactams, quinolones, metronidazole) were significantly shorter for deescalated patients (eSupplement Table 1). Initial therapy was appropriate in $58(97 \%)$ of 60 microbiologically confirmed infections (eSupplement Table 2).

The de-escalation group had a lower mean lactate on ICU admission $(2.4 \pm 2.1$ vs $3.2 \pm 2.3 \mathrm{mmol} / \mathrm{L}$, $P=0.03)$, a lower mean SOFA score on ICU day $5(5.1 \pm 3.9$ vs $7 \pm 3.5$, $P=0.002)$, less history of resistant organisms (3 vs $16 \%, P=0.03$ ), and fewer concomitant multiple infections (16 vs $36 \%, P=0.02$ ) compared to the non de-escalation group. There were no differences in ICU, hospital, or 28-day mortality between the two groups (Table 1). The de-escalation group had shorter ICU (8.1 vs
11.2 days, $P=0.006$ ) and hospital (17.1 vs 23.4 days, $P=0.04$ ) LOS after adjusting for known prognostic factors in a multivariate analysis (eSupplement Table 3).

Our frequency of de-escalation $(58 \%)$ was higher than that of Mokart et al. (44\%), the only other de-escalation study in septic cancer patients [2]. The dissimilarities in study populations may account for the difference in de-escalation rates between our two cancer centers.

In our study, by ICU day 5, the non de-escalation group had a higher mean SOFA score compared to the de-escalated patients, implying slower clinical resolution. One factor that may be influencing the decision to de-escalate is the physician's perception of the clinical progress of the septic patient, and following serial SOFA scores, or other severity-ofillness measures as suggested by Joung et al. [3], may be useful to deescalate patients safely.

In conclusion, de-escalating antimicrobial therapy in septic cancer patients admitted to the ICU from the UCC was associated with shorter ICU and hospital LOS. No adverse effect of de-escalation on mortality was found. Future sepsis studies should focus on investigating whether deescalation can definitively improve patient outcomes and/or slow emerging antimicrobial resistance.

Compliance with ethical standards

Conflicts of interest None of the authors have any financial disclosures or conflicts of interest. 
Table 1 Baseline characteristics and outcomes of de-escalation and non de-escalation groups

\begin{tabular}{|c|c|c|c|}
\hline Variable & $\begin{array}{l}\text { De-escalation } \\
(N=61)\end{array}$ & $\begin{array}{l}\text { Non de-escalation } \\
(N=44)\end{array}$ & $P$ value \\
\hline Age (years) & $62.5( \pm 13.2)$ & $61.7( \pm 12.8)$ & 0.7 \\
\hline Gender (male) & $39(64 \%)$ & $28(64 \%)$ & 1 \\
\hline \multicolumn{4}{|l|}{ Cancer type } \\
\hline Hematologic & $24(39 \%)$ & $17(39 \%)$ & 1 \\
\hline Solid & $37(61 \%)$ & $27(61 \%)$ & \\
\hline Neutropenia on ICU admission & $13(21 \%)$ & $11(26 \%)$ & 0.64 \\
\hline History of antibiotic allergy & $15(25 \%)$ & $8(18 \%)$ & 0.48 \\
\hline Prior history of resistant organism & $2(3 \%)$ & $7(16 \%)$ & 0.03 \\
\hline Lactate level (mmol/L) on ICU admission & $2.4( \pm 2.1)$ & $3.2( \pm 2.3)$ & 0.03 \\
\hline Blood culture on ICU admission that turned positive & $15(25 \%)$ & $7(16 \%)$ & 0.34 \\
\hline $\begin{array}{l}\text { Time to first antibiotic administration } \\
\text { from initial blood culture collection (hours) }\end{array}$ & $1.1( \pm 3)$ & $1( \pm 3)$ & 0.86 \\
\hline Concomitant multiple infections & $10(16 \%)$ & $16(36 \%)$ & 0.02 \\
\hline Use of MV during ICU stay & $29(48 \%)$ & $22(50 \%)$ & 0.84 \\
\hline Use of MV on day 5 & $20(33 \%)$ & $18(41 \%)$ & 0.42 \\
\hline Total MV duration (days) (for those on MV) & $7.1( \pm 3.4)$ & $10.1( \pm 6.6)$ & 0.18 \\
\hline Use of VP during ICU stay & $42(69 \%)$ & $35(80 \%)$ & 0.27 \\
\hline MPM II score on ICU admission & $0.5( \pm 0.2)$ & $0.5( \pm 0.3)$ & 0.96 \\
\hline SOFA score on ICU admission & $7.2( \pm 3.3)$ & $8( \pm 3.4)$ & 0.18 \\
\hline SOFA score on ICU day 5 & $5.1( \pm 3.9)$ & $7( \pm 3.5)$ & 0.002 \\
\hline $\begin{array}{l}\text { Difference between SOFA } \\
\text { on day } 5 \text { and SOFA on ICU admission }\end{array}$ & $-2.1( \pm 3.5)$ & $-1( \pm 3.5)$ & 0.05 \\
\hline Duration of therapy & $13.3( \pm 7.2)$ & $15.5( \pm 11.1)$ & 0.6 \\
\hline ICU mortality & $11(18 \%)$ & $10(23 \%)$ & 0.62 \\
\hline Hospital mortality & $21(34 \%)$ & $15(34 \%)$ & 1 \\
\hline 28-day mortality & $24(39 \%)$ & $15(34 \%)$ & 0.68 \\
\hline ICU LOS & $8.1( \pm 4.6)$ & $11.2( \pm 7.4)$ & 0.001 \\
\hline Hospital LOS & $17.1( \pm 22.9)$ & $23.4( \pm 17.6)$ & 0.005 \\
\hline
\end{tabular}

Data are expressed as number (percentage) or mean ( \pm standard $I C U$ intensive care unit, $L O S$ length of stay, $M V$ mechanical vendeviation). $P<0.05$ was considered significant tilation, MPM mortality probability model, SOFA sequential organ failure assessment, $V P$ vasopressors

Open Access This article is distributed under the terms of the Creative Commons Attribution-NonCommercial 4.0 International License (http://creativecommons.org/ licenses/by-nc/4.0/), which permits any noncommercial use, distribution, and reproduction in any medium, provided you give appropriate credit to the original author(s) and the source, provide a link to the Creative Commons license, and indicate if changes were made.

\section{References}

1. Weiss E, Zahar JR, Lesprit P, Ruppe E, Leone M, Chastre J, Lucet JC, PaugamBurtz C, Brun-Buisson C, Timsit JF, Deescalation Study Group (2015)

Elaboration of a consensual definition of de-escalation allowing a ranking of betalactams. Clin Microbiol Infect 21:649.e1-649.e10. doi: 10.1016/j.cmi.2015.03.013
2. Mokart D, Slehofer G, Lambert J, Sannini A, Chow-Chine L, Brun JP, Berger P, Duran S, Faucher M, Blache JL, Saillard C, Vey N, Leone M (2014) De-escalation of antimicrobial treatment in neutropenic patients with severe sepsis: results from an observational study. Intensive Care Med 40:41-49

3. Joung MK, Lee JA, Moon SY, Cheong HS, Joo EJ, Ha YE, Sohn KM, Chung SM, Suh GY, Chung DR, Song JH, Peck KR (2011) Impact of de-escalation therapy on clinical outcomes for intensive care unit-acquired pneumonia. Crit Care 15:R79. doi:10.1186/cc10072

\section{A. Paskovaty (}

Department of Pharmacy, Memorial Sloan Kettering Cancer Center, 1275 York

Avenue, New York, NY 10065, USA

e-mail: paskovaa@mskcc.org

Tel.: 212-639-7212
S. M. Pastores - N. Kostelecky

Critical Care Medicine Service, Department of Anesthesiology and Critical Care

Medicine, Memorial Sloan Kettering

Cancer Center, New York, NY 10065, USA

\section{E. R. Riedel}

Department of Epidemiology and Biostatistics, Memorial Sloan Kettering Cancer Center, New York, NY 10065, USA

Z. Gedrimaite $\cdot$ S. K. Seo

Infectious Disease Service, Department of Medicine, Memorial Sloan Kettering Cancer Center, New York, NY 10065, USA 